\title{
25 Research Square \\ Study on the thermal kinetics of anthracite oxidation induced by water and associated pyrite
}

\section{Caiping Wang}

Xi'an University of Science and Technology

Xiadan Duan

Xi'an University of Science and Technology

\section{Zujin Bai}

Xi'an University of Science and Technology

Yang Xiao ( $\nabla$ xiaoy212@163.com )

Xi'an University of Science and Technology https://orcid.org/0000-0002-3960-9708

Jun Deng

Xi'an University of Science and Technology

\section{Research}

Keywords: Associated pyrite, Coal spontaneous combustion, Oxidation kinetics, Apparent activation energy, Mechanism model

Posted Date: June 22nd, 2020

DOI: https://doi.org/10.21203/rs.3.rs-37092/v1

License: (c) (i) This work is licensed under a Creative Commons Attribution 4.0 International License.

Read Full License 


\section{Abstract}

Pyrite and water in coal have considerable influence on coal spontaneous combustion and threaten the safety of mine production gravely. To reveal the influence mechanism of water and associated pyrite on oxidation kinetics of coal-oxygen composite reaction, the pyrite of $0 \%, 1 \%, 2 \%, 4 \%, 6 \%$ and the moisture of $1 \%, 5 \%, 10 \%, 15 \%$ and $20 \%$ were mixed with the coal samples to obtain 25 coal samples.

Thermogravimetric analysis technology was conducted to explore the changes of mass and characteristic temperatures of coal samples treated with water and associated pyrite during the lowtemperature oxidation, and kinetic analysis of the oxidation process was discussed based on multiple heating rates $\left(5^{\circ} \mathrm{C} / \mathrm{min}, 10^{\circ} \mathrm{C} / \mathrm{min}\right.$ and $\left.15^{\circ} \mathrm{C} / \mathrm{min}\right)$. The results show that water and associated pyrite had a great influence on coal in oxygen absorption and weight gain stage ( T $3 \sim$ T 5 ), and there was a proportion range with the largest synergistic oxidation contribution. The apparent activation energy of the coal sample appeared changes, but the mechanism model did not, indicating that water and pyrite could affect the oxidation process of the coal sample externally. When water and associated pyrite exhibit synergistic interaction, there have a range that water was 10 15\% and associate pyrite was $2 \sim 4 \%$ had the largest promotion and contribution to anthracite oxidation. The results have important scientific value and practical guiding significance for the further study on prediction, prevention and control of high sulfur anthracite spontaneous combustion.

\section{Introduction}

Coal utilities are currently the major source of electricity in China, and in foreseeable future, coal will continue to be main energy and important industrial raw materials all over the word, and still plays an important role in economic development (Xu et al.2018; Xie et al. 2020). At present, low-sulfur coal is widely exploited and utilized; so, coal of high sulfur may have a significant role to play in future. Sulfur in coal can be divided into organic sulfur and inorganic sulfur; meanwhile, the main form of inorganic sulfur is pyrite $\left(\mathrm{FeS}_{2}\right.$ ) (Yang et al. 2019). In actually anthracite mining process, the content of pyrite increased under the influence of mining depth. At the same time, it was affected by the infiltration of surface and groundwater in the mining process. The air leakage caused by water exploration and release provided enough oxygen for anthracite, which lead to the spontaneous combustion of high-sulfur anthracite (Huang 2013). Burning high-sulfur coal would produce carbon dioxide and sulfur dioxide, they were the main sources of greenhouse gases and acid rain, respectively (Gu et al. 2017; Liang et al. 2019). In order to ensure production safety, reduce energy loss and whilst minimising the impact on the environment, we need to study the influence of water and associated pyrite on coal oxidation process.

Sulfur is promising storage medium, which can be used for thermal energy storage at high temperature with a lower cost, and has good charge-discharge performance at high temperature (Jin et al. 2020; Nithyanandam et al. 2018). As for the influence of pyrite on CSC, studies have found that pyrite has a great influence on low temperature oxidation in humid environment (Arisoy and Beamish 2015; Arisoy et al. 2017). In the past decades, numerous researches have been carried out in learning the effect of pyrite on low-temperature coal oxidation. According to the Fenton reaction, $\mathrm{FeS}_{2}$ in coal reacts with oxygen 
and water, the resulting $\mathrm{H}_{2} \mathrm{SO}_{4}$ and $\mathrm{Fe}(\mathrm{OH})_{3}$ colloids make a difference to CSC (Arisoy et al. 2017; Doulati et al. 2008; Li 2007; Yu et al. 2013). At the same time, the reaction gives off heat, which accumulated continuously and further increased the macroscopic calorific value of coal, promoted coal sample oxidation, and finally caused CSC. In recent years, Deng et al. (2015), Wang et al. (2020) found that pyrite has a significant effect on the spontaneous combustion of coal. The addition of $2.0 \mathrm{mass}_{\mathrm{F}} \mathrm{FeS}_{2}$ exerted a prominent promoting effect on gas coal oxidation, the $5 \sim 7 \% \mathrm{FeS}_{2}$ had a great impact on anthracite. Yang et al. (2019) found that temperatures corresponding to the maximum weight loss and peak temperatures of coal samples were lowered with higher pyrite content, also calculated the apparent activation energy $\left(E_{\mathrm{a}}\right)$ using Flynn-Wall-Ozawa (FWO) method, it was conclude that coal with higher pyrite content was more prone to spontaneous combustion.

Zhang et al. (2020a) have found the external moisture content has a significant impact on coal quality variation in the process of oxidation. The increase of moisture content would make the TG and DSC curve of CSC showing hysteresis, and inhibit the coal oxidation, which is not conducive to CSC (Jia et al. 2020). In addition, water-immersed coal can affect coal initial heat release temperature and heat release in the low temperature oxidation process, compared with raw coal, it was more likely to spontaneously ignite (Zhong et al.2015; Qin et al. 2018; Qiao et al. 2018). Tang et al. (2017) calculated the activation energy of bituminous coal immersed for 30 90 days using Arrhenius Formal, and found that the coal sample released more heat at the low temperature stage, with lower activation energy and easier oxidation than raw coal. At the same time, the structure of coal sample will change to some extent after water immersion.

Domestic and foreign scholars have made some progress in the study of CSC which affected by water and pyrite, and accumulated a good research foundation. However, hardly study on oxidation kinetics effect of water and pyrite on CSC, such as the thermogravimetry, temperature and kinetics in the process of low temperature oxidation. Therefore, on the basis of previous studies, this paper investigated the influence of water and associated pyrite on anthracite mass and characteristic temperature in low temperature oxidation through TG-DTG experiments. In addition, based on the synergistic effect of water and pyrite, the kinetic characteristic parameters of coal oxidation process were calculated and the most probable function was determined. Meanwhile, the mechanism of its effect on anthracite oxidation reaction was revealed, the optimal influence ratio range was also determined; which provided a key support for further inhibiting the oxidation process of pyrite bearing coal from the perspective of thermal reaction.

\section{Experiments And Methods \\ 2.1. Sample preparation}

Taking the anthracite of Baijiao Coal Mine (Sichuan Province, China) as the research object, the fresh and unoxidized coal samples collected from the site were transported to the laboratory in sealed packaging of 
multi-layer plastic and nylon bags. Meanwhile, the fresh coal samples crushed and ground to less than 200 mesh, and each coal sample was ca. 100g.

In order to accurately study the effect of external moisture on coal oxidation at low temperature, the coal sample was dehydrated. The specific method was to dry the coal samples in vacuum at $30^{\circ} \mathrm{C}$ for 48hours.Due to the lower internal moisture of Baijiao anthracite, the influence of internal moisture was not considered. So, different moisture was added to the coal samples after many calculations and experiments. Mixture well and leave in a cool, airtight place for a week until moisture was absorbed. Finally, coal samples with external moisture content of $1 \%, 5 \%, 10 \%, 15 \%$ and $20 \%$ were obtained. Pyrite was crushed to $0.075 \mathrm{~mm}$ and added to the samples in order to gain anthracite samples with pyrite content of $0 \%, 1 \%, 2 \%, 4 \%$ and $6 \%$.

The coal samples with pyrite content were orthogonal to the samples with water content; at the end, 25 coal samples with different moisture and pyrite were obtained, respectively W1P0, W1P1, W1P2, W1P4, W1P6, W5P0, W5P1, W5P2, W5P4, W5P6, W10P0, W10P1, W10P2, W10P4, W10P6, W15P0, W15P1, W15P2, W15P4, W15P6, W20P0, W20P1, W20P2, W20P4, W20P6; wherein W represents water and P for pyrite.

\subsection{Elemental analysis and proximate analysis}

Samples underwent technical and element analysis via a 5E-MAG6700 (Kaiyuan, Changsha, China) proximate analyser and Vario ELIII (Elementar, German) organic element analyser before experiments. The moisture $\left(M_{\mathrm{ad}}\right)$, ash $\left(A_{\mathrm{ad}}\right)$, volatility $\left(V_{\mathrm{ad}}\right)$, fixed carbon $\left(F C_{\mathrm{ad}}\right)$, and element content were presented in Table 1.

\subsection{TG-DTG experiment}

The TG-DTG experiments were carried out from 30 to $400{ }^{\circ} \mathrm{C}$, at heating rates of 5,10 and $15{ }^{\circ} \mathrm{C} / \mathrm{min}$ in air and $\mathrm{N}_{2}$ atmosphere of $50 \mathrm{~mL} / \mathrm{min}$, and the experimental sample volume was $5 \mathrm{mg}$. The TG-DTG curves of coal samples with different water and pyrite were obtained, which showed the different characteristics of coal oxidation at low temperature.

\subsection{Kinetic methods}

In the study of coal oxidation kinetics, the rate of coal weight loss (gain) can be expressed by differential method and integral methods.

$G(a)$ represents the integral of the reaction mechanism function, as shown below. 


$$
G(\alpha)=k t
$$

$f(a)$ represents the differential form of the reaction mechanism function:

$$
d \alpha / d t=k f(\alpha)
$$

According to Arrhenius formula, the relationship between reaction constant and temperature (absolute temperature) is:

$$
k=A \exp \left(-E_{a} / R T\right)
$$

The experiment adopts non-isothermal temperature rise, so $T=T_{0}+\beta$. The simultaneous Eqs. (1-3), are summarized to obtain the kinetic expression of the solid-gas two phase under non-isothermal heating conditions (Hu et al. 2008):

$$
d \alpha / d t=\frac{A}{\beta} f(\alpha) \exp \left(-E_{a} / R T\right)
$$

Where, $R$ is the universal gas constant, $8.314 \mathrm{~J} /(\mathrm{mol} \cdot \mathrm{K}) ; \beta$ is the heating rate, $\mathrm{K} / \mathrm{min} ; E_{\mathrm{a}}$ is the apparent activation energy; $a$ is the conversion rate of coal at time, $\mathrm{t}$; is the pre-exponential factor.

(1) Achar differentiation

Integrate both sides of Eq. (1) and take the logarithm to get:

$$
\ln \frac{d \alpha}{f(\alpha) d T}=\ln \frac{A}{\beta}-\frac{E_{\alpha}}{R T}
$$

(2) Group-Redfern integral method

$$
\begin{gathered}
\mathrm{n}=1, \ln \left[\frac{G(\alpha)}{T^{2}}\right]=\ln \left(\frac{A R}{\beta E_{a}}\right)-\frac{E_{a}}{R T} \\
\mathrm{n} \neq 1, \ln \left[\frac{1-(1-\alpha)}{T^{2}}\right]=\ln \left(\frac{A R}{\beta E_{a}}\right)-\frac{E_{a}}{R T}
\end{gathered}
$$

In this paper, $n=1$. Eq. (4) and Eq. (6) were fitted linearly respectively to calculate the apparent activation energy and the pre-exponential factor. 


\section{Results And Discussion}

\subsection{Characterization of coal samples}

Through proximate and elemental analysis of raw coal (YM), and 25 experimental coal samples, indexes of each element, moisture and ash were obtained, as shown in Table 1. In raw coal, the content of $C$ was higher, while $\mathrm{H}$ was lower; it indicated that Baijiao anthracite had a high degree of metamorphism. Meanwhile, the lower content of $O$ in raw coal, which was only $1.51 \%$, suggested the oxygen condition of spontaneous combustion of raw coal was relatively low (Song et al. 2019).

With the increase of moisture content, the content of $\mathrm{O}$ and $\mathrm{H}$ increased accordingly, and it was greatest when water content was 1 5\%. Hence, the increased of moisture content will lead to the increase of oxygen-containing functional groups. According to Table 1, it could be concluded that the increase of pyrite content would increase sulfur in coal, which may enhance the environmental impact of sulfur oxide $\left(\mathrm{SO}_{\mathrm{X}}\right)$ release. Conversely, the impact on other elements was small. The $V_{\mathrm{ad}}$ showed a trend of decrease after the first increase, this was because the water in coal and pyrite would have a synergistic reaction, with the increased of water, the production such as $\mathrm{CO}_{2}$ will increase. The variation was strongest at about $10 \%$ moisture. After that, the water film and vapor pressure (Arisoy et al. 2017; Yu et al.2013) would be produced due to excessive water, and the changing effect will be weakened.

Table 1 Coal samples analysis 


\begin{tabular}{|c|c|c|c|c|c|c|c|c|c|}
\hline \multirow[t]{2}{*}{ Sample } & \multicolumn{5}{|c|}{ Elemental analysis (\%) } & \multicolumn{4}{|c|}{ Proximate analysis (\%) } \\
\hline & $\mathrm{C}$ & $\mathrm{H}$ & 0 & $\mathrm{~N}$ & $S$ & $M_{\mathrm{ad}}$ & $A_{\mathrm{ad}}$ & $V_{\text {ad }}$ & $F C_{\mathrm{ad}}$ \\
\hline YM & 90.47 & 3.21 & 1.51 & 2.80 & 2.01 & 1.40 & 26.02 & 8.85 & 63.73 \\
\hline W1P0 & 89.69 & 3.61 & 1.71 & 2.85 & 2.14 & 2.32 & 25.49 & 9.10 & 63.39 \\
\hline W1P1 & 88.96 & 3.49 & 1.59 & 2.75 & 3.21 & 2.30 & 25.34 & 9.01 & 63.35 \\
\hline W1P2 & 88.43 & 3.45 & 1.35 & 2.52 & 4.25 & 2.29 & 24.92 & 9.23 & 63.56 \\
\hline W1P4 & 86.25 & 3.58 & 1.24 & 2.59 & 6.34 & 2.34 & 25.54 & 8.92 & 63.20 \\
\hline W1P6 & 84.69 & 3.48 & 1.2 & 2.34 & 8.29 & 2.21 & 25.8 & 8.98 & 63.01 \\
\hline W5P0 & 86.98 & 5.82 & 3.01 & 2.21 & 1.98 & 6.27 & 24.96 & 9.49 & 60.15 \\
\hline W5P1 & 87.00 & 5.58 & 2.98 & 2.19 & 2.25 & 6.30 & 24.22 & 9.28 & 60.20 \\
\hline W5P2 & 85.96 & 5.36 & 2.78 & 2.12 & 3.78 & 6.28 & 24.19 & 9.38 & 60.15 \\
\hline W5P4 & 84.26 & 5.29 & 2.68 & 2.09 & 5.68 & 6.27 & 24.04 & 9.58 & 60.19 \\
\hline W5P6 & 82.32 & 5.3 & 2.78 & 2.01 & 7.59 & 6.19 & 24.19 & 9.54 & 60.08 \\
\hline W10P0 & 84.51 & 6.54 & 4.26 & 2.8 & 1.89 & 9.73 & 24.01 & 9.02 & 57.24 \\
\hline W10P1 & 83.77 & 6.52 & 4.21 & 2.75 & 2.75 & 9.80 & 24.18 & 9.01 & 57.01 \\
\hline W10P2 & 83.25 & 6.01 & 4.32 & 2.83 & 3.59 & 9.68 & 24.22 & 8.89 & 57.21 \\
\hline W10P4 & 81.71 & 5.95 & 4.01 & 2.65 & 5.68 & 9.59 & 24.21 & 8.80 & 57.40 \\
\hline W10P6 & 80.13 & 5.69 & 3.73 & 2.32 & 8.13 & 9.46 & 24.31 & 9.04 & 57.19 \\
\hline W15P0 & 83.08 & 7.61 & 5.45 & 2.18 & 1.68 & 14.95 & 22.30 & 8.82 & 53.93 \\
\hline W15P1 & 82.35 & 7.52 & 5.42 & 2.12 & 2.59 & 14.89 & 22.47 & 8.75 & 53.89 \\
\hline W15P2 & 82.59 & 7.21 & 5.38 & 2.10 & 2.72 & 14.58 & 22.66 & 8.98 & 53.78 \\
\hline W15P4 & 80.05 & 7.09 & 5.28 & 1.99 & 5.59 & 14.99 & 22.36 & 8.69 & 53.96 \\
\hline W15P6 & 78.35 & 7.01 & 5.16 & 1.89 & 7.59 & 15.01 & 22.19 & 8.78 & 54.02 \\
\hline W20P0 & 80.83 & 8.94 & 6.66 & 2.08 & 1.49 & 19.59 & 20.96 & 8.31 & 51.14 \\
\hline W20P1 & 80.5 & 8.54 & 6.56 & 2.02 & 2.38 & 19.60 & 20.99 & 8.29 & 51.12 \\
\hline W20P2 & 79.95 & 8.21 & 6.4 & 2.12 & 3.32 & 19.55 & 18.16 & 8.19 & 54.10 \\
\hline W20P4 & 78.49 & 8.01 & 6.23 & 1.98 & 5.29 & 19.45 & 17.99 & 8.40 & 54.16 \\
\hline W20P6 & 76.07 & 8.75 & 6.01 & 1.58 & 7.59 & 19.44 & 18.06 & 8.30 & 54.20 \\
\hline
\end{tabular}




\subsection{Characteristics temperatures}

The TG and derivative-TG (DTG) curves during coal oxidation process were presented in Figs. 1-3. It should be illustrated that this paper took the heating rate of $10^{\circ} \mathrm{C} / \mathrm{min}$ as an example to research the influence of water and associated pyrite on TG-DTG curve. As shown in Fig. 1, coal generally have five temperature points during the oxidation process at low temperature: $T_{1}, T_{2}, T_{3}, T_{4}$, and $T_{5}$, correspondingly to the temperatures of the maximum evaporation of water and desorption of gases, minimum weight loss on TG curve, coal sample began to gain weight, maximum oxidization mass gain, ignition point, respectively (Deng et al. 2017; Yang et al. 2018; Zhao et al. 2019a). Combined with the change of weight loss rate of TG-DTG curve, coal oxidation process could be divided into four stages: water evaporation and desorption stage $\left(T_{1} \sim T_{2}\right)$, dynamic equilibrium stage $\left(T_{2} \sim T_{3}\right)$, oxygen absorption and weight gain stage $\left(T_{3} \sim T_{5}\right)$, and thermal decomposition stage (after $T_{5}$ ) (Zhao et al. 2019b).

The characteristic temperatures of all samples were presented in Fig. 2, the temperatures of the maximum evaporation of water and desorption of gases of 25 coal samples ranged from $90{ }^{\circ} \mathrm{C}$ to 110 ${ }^{\circ} \mathrm{C}$. Under the different moisture content and with the increase of pyrite, $T_{1}$ was reduced, although the change was nonlinear. When the moisture content increased, the critical temperature displayed a trend of increasing first and then decreasing. This was because the increase of water content leads to the increase of water evaporation in the early stage of low-temperature oxidation and the longer evaporation time. However, it was not the higher the moisture content, the higher the critical temperature. There was a critical moisture content in this experiment, which was 10 15\%.

With the increase of pyrite which in different water content, the variation trend of $T_{2}$ was different. When pyrite content was less than $6 \%$, with the increase of moisture content, the $T_{2}$ first fall and then rose and then decreased, reached the lowest value at $5 \%$, and reached the highest temperature when the water content was 10 15\%. According to Fig. 2, the dry cracking temperature of 25 coal samples were about $105 \sim 126^{\circ} \mathrm{C}$, and the increase of pyrite content would raise the temperature to a certain extent.

Started from $T_{3}$, the oxidation of coal became intense, which was the starting of oxygen absorption and weight gain stage of coal sample. The variation of $T_{3}$ was shown in Fig. 3a, under the $20 \%$ of moisture content, the temperature of coal samples was lower when pyrite content was $2 \sim 4 \%$. Meanwhile, with the increase of moisture content, the trend of $T_{3}$ was different, among which the coal samples with water content of $10 \%$ and $15 \%$ had lower temperature. The change of temperature was affected by many factors, on one hand, the products $\mathrm{Fe}(\mathrm{OH})_{3}$ colloid under reaction of pyrite and oxygen in damp environment (Arisoy et al. 2017; Yu et al. 2013) filled the coal inner pore and prevented coal oxidation; on the other hand the reaction of pyrite and water produced $\mathrm{H}_{2} \mathrm{SO}_{4}$, a large amount of $\mathrm{H}^{+}$liquid film made the coal molecules in an oxygen-rich environment and active groups advanced to participate in reaction (Zhang et al. 2020b). 
By observing $T_{4}$ of 25 coal samples, it was viewed that the temperature was within $278 \sim 330^{\circ} \mathrm{C}$, and temperature variation was nonlinear. W10P2, W1P2 and W1P0 had smaller $T_{4}$ in all coal samples. Due to the comprehensive effects of pyrite and $\mathrm{O}_{2}$ reaction products, water and oxygen complex and other factors, the temperature of maximum oxidization mass gain was not the same.

$T_{5}$ was the temperature represented the maximum value of sample mass ratio, which the number of active groups and the adsorption amount of oxygen in the coal reached the maximum. Notably, as presented in Fig. 3b, when moisture content was greater than $1 \%, T_{5}$ was first decreased, then increased and last decreased with the increase of pyrite content, and it was smaller when the pyrite content was $2 \sim 4 \%$. When pyrite content less than $6 \%, T_{5}$ was first rose and then fall and finally rose with the raise of moisture content, and was lower at 10 15\%. The reason for this was the reaction between water and pyrite could give off heat, when water content was 10 15\%, it could fully react with the $2 \sim 4 \%$ pyrite. Under the influence of heat release, the active groups that were originally not involved in coal oxygen reaction at a lower temperature also began to participate in the reaction and reached the ignition temperature in early. $T_{5}$ was within the range of $368 \sim 388^{\circ} \mathrm{C}$, especially the temperature of coal samples W1P0, W5P6 and W20P6 were relatively low (Fig. 2).

\subsection{Variation of coal mass}

In order to further research the impact of water and associated pyrite on coal low temperature oxidation, the mass changes in different stages on the TG curve were observed, date in Table 2 shown the mass change of two stages (Deng et al.2018a).

Table 2 Mass variation of coal samples at different stages in the heating process 


\begin{tabular}{|c|c|c|c|c|c|}
\hline \multirow[t]{2}{*}{ Sample } & \multicolumn{2}{|c|}{ Water evaporation and desorption } & \multicolumn{3}{|c|}{ Oxygen absorption and weight gain } \\
\hline & $T_{2}\left({ }^{\circ} \mathrm{C}\right)$ & $\Delta M_{1}(\%)$ & $T_{3}\left({ }^{\circ} \mathrm{C}\right)$ & $T_{5}\left({ }^{\circ} \mathrm{C}\right)$ & $\Delta M_{2}(\%)$ \\
\hline W1P0 & 114.1 & 0.12 & 127.7 & 368.2 & 2.14 \\
\hline W1P1 & 116.7 & 0.13 & 135.9 & 371.3 & 2.20 \\
\hline W1P2 & 113.3 & 0.16 & 133.1 & 377.1 & 2.22 \\
\hline W1P4 & 118.1 & 0.19 & 137.2 & 370.7 & 2.24 \\
\hline W1P6 & 118.7 & 0.18 & 134.2 & 378.7 & 2.25 \\
\hline W5P0 & 109.0 & 0.14 & 130.1 & 387.7 & 2.17 \\
\hline W5P1 & 109.8 & 0.16 & 131.0 & 374.7 & 2.22 \\
\hline W5P2 & 108.3 & 0.17 & 126.1 & 379.3 & 2.36 \\
\hline W5P4 & 122.5 & 0.21 & 130.2 & 374.6 & 2.30 \\
\hline W5P6 & 112.4 & 0.16 & 132.4 & 369.4 & 2.20 \\
\hline W10P0 & 120.0 & 0.18 & 131.5 & 383.9 & 2.23 \\
\hline W10P1 & 115.5 & 0.20 & 133.9 & 373.8 & 2.36 \\
\hline W10P2 & 123.6 & 0.24 & 133.5 & 374.4 & 2.46 \\
\hline W10P4 & 113.8 & 0.25 & 126.7 & 386.5 & 2.47 \\
\hline W10P6 & 119.0 & 0.24 & 128.7 & 378.6 & 2.36 \\
\hline W15P0 & 110.8 & 0.19 & 134.6 & 375.8 & 2.36 \\
\hline W15P1 & 118.0 & 0.21 & 130 & 375.6 & 2.43 \\
\hline W15P2 & 116.8 & 0.26 & 128.9 & 373.0 & 2.49 \\
\hline W15P4 & 116.3 & 0.24 & 131.0 & 380.6 & 2.46 \\
\hline W15P6 & 109.5 & 0.19 & 134.3 & 372.7 & 2.30 \\
\hline W20P0 & 117.7 & 0.14 & 133.7 & 380.3 & 2.18 \\
\hline W20P1 & 115.0 & 0.19 & 136.3 & 372.1 & 2.35 \\
\hline W20P2 & 122.0 & 0.17 & 142.5 & 379.9 & 2.36 \\
\hline W20P4 & 126.4 & 0.18 & 135.6 & 373.8 & 2.34 \\
\hline W20P6 & 116.9 & 0.22 & 133.5 & 369.5 & 2.38 \\
\hline
\end{tabular}

Note: $\Delta M_{1}$ : The loss ratio of water evaporation and desorption stage; $\Delta M_{2}$ : The loss ratio of oxygen absorption and weight gain stage 


\subsubsection{Mass change during evaporation and desorption stage}

As shown in Table 2, under the different moisture content, as pyrite increased, the mass changes in the water evaporation and desorption stage was first increased and then decreased and finally increased, and the mass was the largest when the water content was 10 15\%; meanwhile, the maximum change was achieved when pyrite was 2 4\% (Fig. 4a). After $\mathrm{T}_{1}$, larger active group in coal began to react with oxygen and generate $\mathrm{CO}$ and $\mathrm{CO}_{2}$, at this time, the reaction rate of pyrite with $\mathrm{O}_{2}$ was also accelerated, which made the gas generation and consumption rate achieve balance. Finally, the mass changes of coal became stability. The variation of coal mass affect by many factors, such as the evaporation of coal water, the production of water-oxygen complex and the generation of pyrite with oxygen.

Observing the mass changes of 25 coal samples in water evaporation and gas desorption stage, discovered the mass changes of coal samples ranged from 0.12 to $0.26 \%$, among which the mass changes of coal sample W15P2 was the largest, followed by W10P4, $0.25 \%$,and then mass variation of W10P2, W10P6 and W15P4 were $0.24 \%$. Therefore, when pyrite content was $2 \sim 4 \%$ and water was $10 \sim 15 \%$, it had the strongest ability to promote the oxidation of coal in the water evaporation and desorption stage.

\subsubsection{Mass change during oxygen absorption and weight gain stage}

Under different moisture content, with the rise of pyrite content, the sample mass generally showed a trend of increasing first and then decreasing and last increasing, and the weight gain was the largest when water was 10 15\%.At the same time, the weight gain was the largest when the pyrite content was $2 \sim 4 \%$ (Fig. 4b). Coal oxidation is a complex chemical interplay and temperature is the most crucial factor affecting the reaction process. After $T_{3}$, coal samples entered into a violent oxidation stage, and the oxygen uptake increased continuously. In the process of oxidation, $2 \sim 4 \%$ pyrite reacted with 10 15\% water in the coal, eventually advancing the oxidation process and lowering the temperature. Therefore, the mass variation of $2 \sim 4 \%$ pyrite and $10 \sim 15 \%$ moisture coal samples will also be large at this stage. Meanwhile, $15 \%$ moisture was the critical water content in this paper. When the water content was lower than $15 \%$, due to the swelling effect of water on coal, the pores inside the coal and water-oxygen complex generated in the initial stage of coal oxidation increased, which accelerated the oxidation reaction of coal samples (Liu et al. 2016). On the contrary, when the water was too large, the formation of liquid film prevented the coal oxidation, at the end, the variation of coal samples gradually decreased.

The mass change of 25 coal samples in oxygen absorption and weight gain stage was ranged from 2.14 2.49\%. The larger mass change of coal samples was: W15P2 > W10P4 > W15P4, W10P2, W10P6. The results showed that the synergistic effect of pyrite $2 \sim 4 \%$ and moisture 10 15\% was the strongest in promoting the oxidation of coal at the oxygen absorption and weight gain stage.

\subsection{Kinetic parameters}


The coal oxidation reaction was the sum of complex primitive reactions. Activation energy was a very important kinetic parameter in coal oxidation, which can reflect the coal reaction difficulty to a certain extent. A great deal of work has been done (Qi et al. 2015; Deng et al. 2018b) in the study of oxidation reaction kinetics to obtain different methods for solving $E_{\mathrm{a}}, A$ and deducing the most probable mechanism function.In this paper, Achar differential method and Coastal-Redfern integral method were used for kinetic analysis and calculation of coal oxidation reaction, and Bagchi method was used to infer the reaction mechanism function. The experimental data and the 18 solid reaction mechanism functions in the Table 3 were substituted into Eq. (5) and Eq. (7). The fitting curves of $\ln \left[G(a) / T^{2}\right]$ and $\ln [(d a / d T) / f(1 / T)]$ of different coal samples in the oxygen absorption and weight gain stage were obtained. The fitting curves of some coal samples were shown in Fig. 5.

\section{Due to technical limitations, Table 3 is provided in the Supplementary Files section.}

Table 4 summarized the differential and integral results of sample W1P0 under 18 mechanism functions at $10^{\circ} \mathrm{C} / \mathrm{min}$.

Table 4 Differential and integral kinetic parameters of W1P0 under different mechanism functions 


\begin{tabular}{|lllllll|}
\hline Function & $f(a)$ & & \multicolumn{5}{l|}{$G(a)$} \\
\cline { 2 - 5 } & $R$ & $E_{\mathrm{a}}(\mathrm{J} / \mathrm{mol})$ & $A$ & $R$ & $E_{\mathrm{a}}(\mathrm{J} / \mathrm{mol})$ & $A$ \\
\hline 1 & $/$ & $/$ & $/$ & $/$ & $/$ & $/$ \\
\hline 2 & $/$ & $/$ & $/$ & $/$ & $/$ & $/$ \\
\hline 3 & $/$ & $/$ & $/$ & $/$ & $/$ & $/$ \\
\hline 4 & 0.978 & 194988 & 895522 & 0.981 & 193042 & 772540 \\
\hline 5 & 0.910 & 159820 & 654311 & 0.932 & 108927 & 458521 \\
\hline 6 & 0.852 & 201542 & 895621 & 0.821 & 156982 & 805692 \\
\hline 7 & 0.935 & 215982 & 698548 & 0.952 & 189651 & 785692 \\
\hline 8 & 0.896 & 201896 & 589652 & 0.856 & 202590 & 586348 \\
\hline 9 & $/$ & $/$ & $/$ & $/$ & $/$ & $/$ \\
\hline 10 & $/$ & $/$ & $/$ & $/$ & $/$ & $/$ \\
\hline 11 & 0.896 & 218974 & 658921 & 0.895 & 198653 & 569899 \\
\hline 12 & $/$ & $/$ & $/$ & $/$ & $/$ & $/$ \\
\hline 13 & $/$ & $/$ & $/$ & $/$ & $/$ & $/$ \\
\hline 14 & 0.893 & 159352 & 489235 & 0.935 & 158935 & 485635 \\
\hline 15 & 0.932 & 189621 & 459863 & 0.893 & 186325 & 489658 \\
\hline 16 & $/$ & $/$ & $/$ & $/$ & $/$ & $/$ \\
\hline 17 & $/$ & $/$ & $/$ & $/$ & $/$ & $/$ \\
\hline 18 & $/$ & $/$ & $/$ & $/$ & $/$ & $/$ \\
\hline
\end{tabular}

Note: / is directly exclude, as have the lower fitting degree from the differential or integral phase

By comparing integration and differentiation, the mechanism function with a larger fitting degree and a similar slope was taken; $E_{\mathrm{a}}$ and $A$ were finally calculated according to the curve. The average apparent activation energy and pre-exponential factor of each coal sample were finally obtained in the oxygen absorption and weight gain stage, as shown in Table 5. Accordingly to the average apparent activation energy, the most probable mechanism function was finally determined, which was $n=4$ Avrami-Erofeev.

From Table 5, it could be found that $E_{\mathrm{a}}$ was first decreased and then increased, and minimal at $2 \%$ pyrite. Besides, $E_{\mathrm{a}}$ was the minimum when sample water was 10 15\%, coal samples needed the small energy for oxidation in this content and were more prone to chemical reactions (Fig.6). While the moisture content was $15 \%$, the apparent activation energy started to increase, which implied that $15 \%$ was the 
sample critical point of the oxidation activity. On the whole, it could be conclude that when the coal sample was synergistically affected by water and pyrite, $E_{\mathrm{a}}$ decreased as a whole, and the oxidation activity increased. There were critical content points of water and pyrite, which were $15 \%$ and $2 \%$, respectively. In addition, it suggested that the chemical reaction of water and pyrite on coal active groups brings changes, which was manifested as the changes of apparent activation energy in the oxidation process. In this stage, coal molecules needed less energy to complete the coal oxygen adsorption reaction.

\section{Due to technical limitations, Table 5 is provided in the Supplemtneary Files section.}

Based on the analysis of sample probable mechanism, the mechanism function of different water and pyrite coal samples did not change during this stage. It implied that although water and associated pyrite can promote the process of coal oxidation, the reaction mechanism was not changed; water and pyrite can affect the degree of coal oxidation, but it does not fundamentally change the oxidation mechanism.

\subsection{Reaction mechanism}

Low temperature oxidation of coal sample is a complex chemical reaction. When coal contains different water and associated pyrite, the coal characteristics will change correspondingly, such as the increase of oxygen-containing functional group and volatile component. All of these will affect coal oxidation, and finally present the changes of characteristic temperatures, coal weight, and so on, in the oxidation process. It can be found from the study that, as shown in Fig. 7, water and pyrite can react chemically and give off heat in coal. Under the comprehensive action of reaction heat and moisture wetting heat, the speed of coal water evaporation was accelerated, made the critical temperature reduce and coal sample began to release heat and gases. At the initial stage of oxidation, the water in the coal sample continued to evaporate, and the oxidation reaction was relatively gentle and the heat generation and gases was less. Meanwhile, under the influence of pyrite, $T_{2}$ had a certain increase, coal samples from $T_{3}$ began a strong coal reaction. Under the dual action of water and pyrite reaction product $\mathrm{Fe}(\mathrm{OH})_{3}$ colloid to fill the pore structure of coal samples, blocked coal oxygen reaction, water and oxygen complex and $\mathrm{H}_{2} \mathrm{SO}_{4}$ acid solution to promote coal oxygen reaction, $T_{5}$ was in advance. At the same time, when water was 10 15\% and pyrite was $2 \sim 4 \%$, the oxidation of anthracite required the least activation energy and the strongest oxidation reaction.

\section{Conclusion}

Coal spontaneous combustion has always been a difficult problem all over the word. Water and associated pyrite is of significance for coal mining, transport and utilizing. The influence of water and associated on coal oxidation had investigated through TG-DTG experiment and dynamic calculation. It was found that water and associated pyrite could not change the oxidation reaction mechanism of coal, but could accelerate or delay coal oxidation process, and it had a great influence on the oxygen 
absorption and weight gain stage $\left(126 \sim 388{ }^{\circ} \mathrm{C}\right)$. Coal oxidation process affected by water and associated pyrite was consistent with the $n=4$ Avrami-Erofeev equation. It was also observed that the synergistic effect of water 10 15\% and pyrite content $2 \sim 4 \%$ had the strongest effect on coal oxidation. In summary, the content of water and pyrite will affect the spontaneous ignition time of anthracite coal seam, we should pay close attention to the content of water and associated pyrite during mining.

\section{Declarations}

\section{Acknowledgment}

This work was supported by the National Key Research and Development Plan of China (No. 2018-YFC0807900), the National Natural Science Foundation of China (No. 5197-4234), Shaanxi Provincial Innovative Talent Promotion Plan-Youth Science and Technology Rising Star Project (No. 2019KJXX0500), Xi'an University of Science and Technology Outstanding Youth Fund (2019YQ2-03), and Shaanxi University Youth Outstanding Talent Support Program.

\section{Conflicts of interest}

The authors declare that they have no conflict of interest.

\section{References}

1. Arisoy A, Beamish B (2015) Mutual effects of pyrite and moisture on coal self-heating rates and reaction rate data for pyrite oxidation. Fuel 139: 107-114

2. Arisoy A, Beamish B, Yoruk B (2017) Moisture moderation during coal self- Fuel 210: 352-358

3. Doulati AF, Jodieri SB, Moradzadeh A, Soleimanet E, Ansari JM (2008) A combined mathematical geophysical model for prediction of pyrite oxidation and pollutant leaching associated with a coal washing waste dump. Int J Environ Sci Technol 15(4): 517-526

4. Deng J, Ma XF, Zhang YT, Li QW, Zhu WW (2015) Effects of pyrite on the spontaneous combustion of coal. Coal Sci Technol 2(4): 306-311

5. Deng J, Li B, Xiao Y, Ma L, Wang CP, Laiwang B, Shu CM (2017) Combustion properties of coal gangue using thermogravimetry-Fourier transform infrared spectroscopy. Appl Therm Eng 116: 244-252

6. Deng J, Ren LF, Ma L, Lei CK, Wei GM, Wang WF (2018a) Effect of oxygen concentration on lowtemperature exothermic oxidation of pulverized coal. Thermochim Acta 667: 102-111

7. Deng J, Bai ZJ, Xiao Y, Shu CM (2018b) Effects on the activities of coal microstructure and oxidation treated by imidazolium-based ionic liquids. J Therm Anal Calorim 133: 453-463

8. Gu Y, Yperman J, Vandewijngaarden J, ReggersG, CarleerR (2017) Organic and inorganic sulphur compounds releases from high-pyrite coal pyrolysis in $\mathrm{H}_{2}, \mathrm{~N}_{2}$ and $\mathrm{CO}_{2}$ : Test case Chinese LZ coal. Fuel 202: 494-502 
9. Hu ZY, Gao SL, Zhao QF, Shi QZ, Zhang TL, Zhang JJ (2008) Thermal analysis kinetics. Science Press, Beijing

10. Huang HJ (2013) Experimental study on coal spontaneous combustion characteristic parameters affected by pyrite sulfur. Dissertation, Xi'an University of Science and Technology

11. Jia YG, Lou HZ, Liu J, Qu GN (2020) Experimental study on thermal characteristics of spontaneous combustion process of coal with different moisture. J China Coal Sochttps://doi.org/10.13225/j.cnki.jccs.2019.1080

12. Jin KY, Wirz RE (2020) Sulfur heat transfer behavior in vertically-oriented and nonuniformly-heated isochoric thermal energy storage systems. Appl Energy https://doi.org/10.1016/j.apenergy.2019.114287

13. Li ZJ (2007) Investigation on the mechanism of spontaneous combustion for sulphide ores and the key technologies for preventing fire. Dissertation, Central South University

14. Liu JF, Peach CJ, Spiers CJ (2016) Anisotropic swelling behaviour of coal matrix cubes exposed to watervapour: Effects of relative humidity and sample size. Int J Coal Geol 167:119-135

15. Liang XH, Wang QH, Luo ZY, Eddings E, Ring T, Li SM, Lin JJ, Xue S, Han L, Xie GL (2019) Experimental and numerical investigation on sulfur transformation in pressurized oxy-fuel combustion of pulverized coal. Appl Energy https://doi.org/10.1016/j.apenergy.2019.113542

16. Nithyanandam K, Barde A, Lakeh R B, Wirz R E (2018) Charge and discharge behavior of elemental sulfur in isochoric high temperature thermal energy storage systems. Appl Energy 214: 166-177

17. Qi GS, Wang DM, Zheng KM, Xu J, Qi XY, Zhong XX (2015) Kinetics characteristics of coal lowtemperature oxidation in oxygen-depleted air. J Loss Prevent Proc 35: 224-231

18. Qin BT, Song S, Qi XY, Zhong XX, Song C (2018) Effect of soaking process on spontaneous combustion characteristics of long-flame coal. J China Coal Soc 43(5): 1350-1357

19. Qiao L, Deng CB, Zhang X, Wang XF, Dai FW (2018) Effect of soaking on coal oxidation activation energy and thermal effect. J China Coal Soc 9: 2518-2524

20. Song YW, Yang SQ, Xu Qin, Cai JW, Hu XC, Song NW, Zhang ZC (2019) Effect of low-temperature oxidation of coal with different metamorphic degrees on coal quality characteristics and outburst comprehensive index. Process Saf Environ Prot 132:142-152

21. Tang YB, Li YF, Xue S, Wang JF, Li RC (2017) Experimental investigation of long-term water immersion effect on spontaneous combustion parameters and microscopic characteristics of bituminous. J China Coal Soc 42(10): 2641-2648

22. Wang CP, Bai ZJ, Deng J, Shu CM, Li QW (2020) Effects of FeS ${ }_{2}$ on the characteristics of coal oxidation at low temperatures. Process Saf Environ Prot https://doi.org/10.1080/00102202.2020.1753715

23. Xu J, Tang H, Su S, Liu JW, Xu K, Qian K, Wang Y, Zhou YB, Hu S, Zhang AC, Xiang J (2018) A study of the relationships between coal structures and combustion characteristics: The insights from micro-Raman spectroscopy based on 32 kinds of Chinese coals. Appl Energy 214: 46-56 
24. Xie HP, Wu LX, Zheng DZ (2019) Prediction on the energy consumption and coal demand of China in 2025. J China Coal Soc 44(7): 1946-1960

25. Yu JL, Tahmeasebi A, Han YN, Yin FK, Li XC (2013) A review on water in low rank coals: The existence, interaction with coal structure and effects on coal utilization. Fuel Process Technol 106: 9-20

26. Yang Y, Deng J, Zhang YN (2018) Oxidation characteristics of coal by STA-FTIR experiment. J China Coal Soc 43(04): 134-143

27. Yang FQ, Lai W, Song YZ (2019) Determination of the influence of pyrite on coal spontaneous combustion by thermodynamics analysis. Process Saf Environ Prot 129: 163-167

28. Zhong XX, Kan L, Xin HH, Qin BT, Dou GL (2015) Thermal effects and active group differentiation of low-rank coal during low-temperature oxidation under vacuum drying after water immersion. Fuel I236: 1204-1212

29. Zhao JY, Deng J, Song JJ, Shu CM (2019a) Effectiveness of a high-temperature-programmed experimental system in simulating particle size effects on hazardous gas emissions in bituminous coal. Safety Sci 115: 353-361

30. Zhao JY, Deng J, Chen L, Wang T, Song JJ, Zhang YN, Shu CM, Zeng Q (2019b) Correlation analysis of the functional groups and exothermic characteristics of bituminous coal molecules during hightemperature oxidation. Energy 185: 136-147

31. Zhang XY, Zhang YL, Wang JF, Hao HD, Wu YG, Zhou CS (2020a) Study on the effect and mechanism of foreign moisture on coal spontaneous combustion. J Fuel Chem Techno 48(1): 1-10

32. Zhang HR, Niu J, Yin X, Guo YX, Cheng FQ (2020b) Role of inherent pyrite in coal on physicochemical structure of activated carbon and adsorption capacity. Fuel https://doi.org/10.1016/j.fuel.2019.116527

\section{Figures}



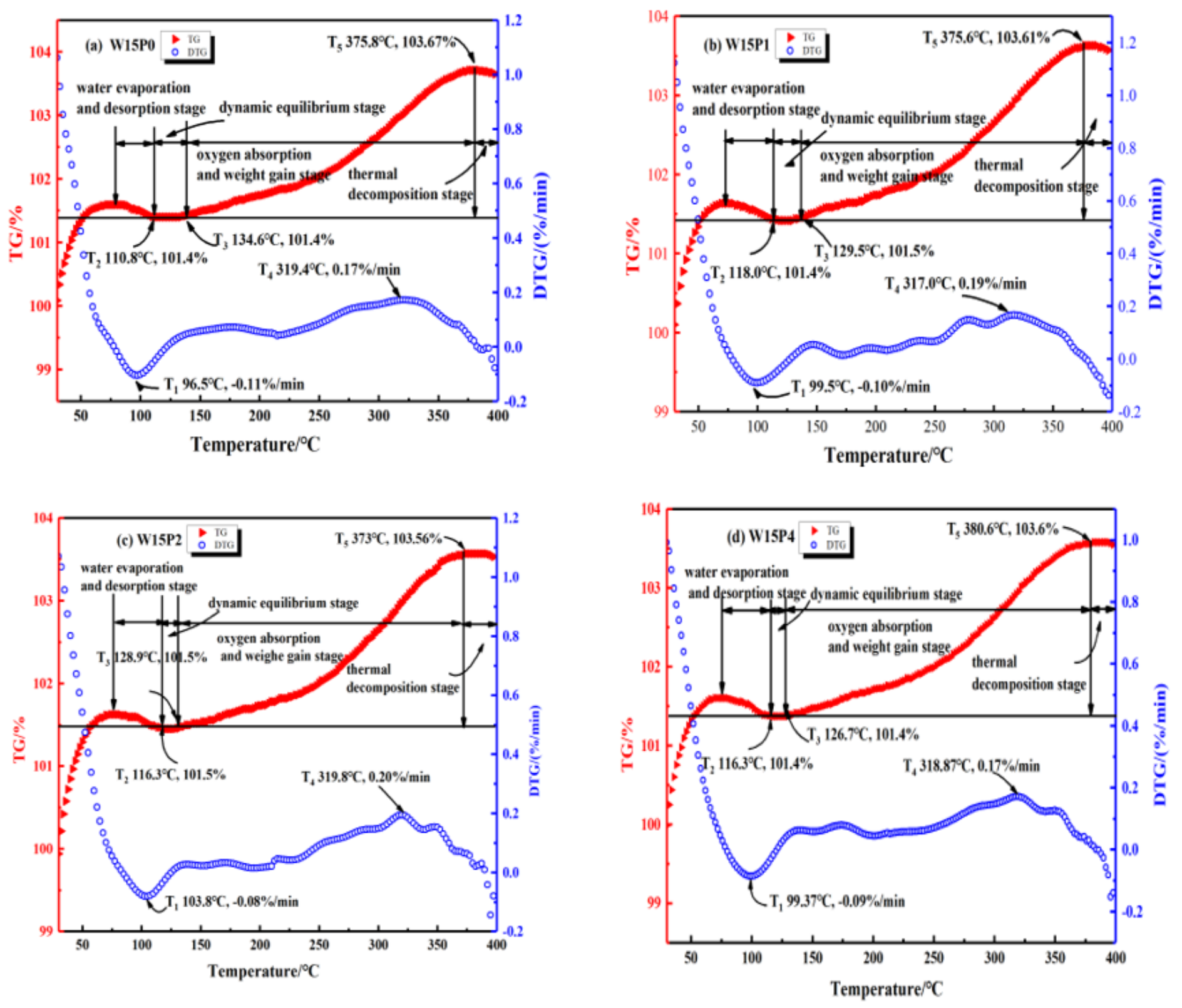

Figure 1

TG-DTG curve of some coal samples 


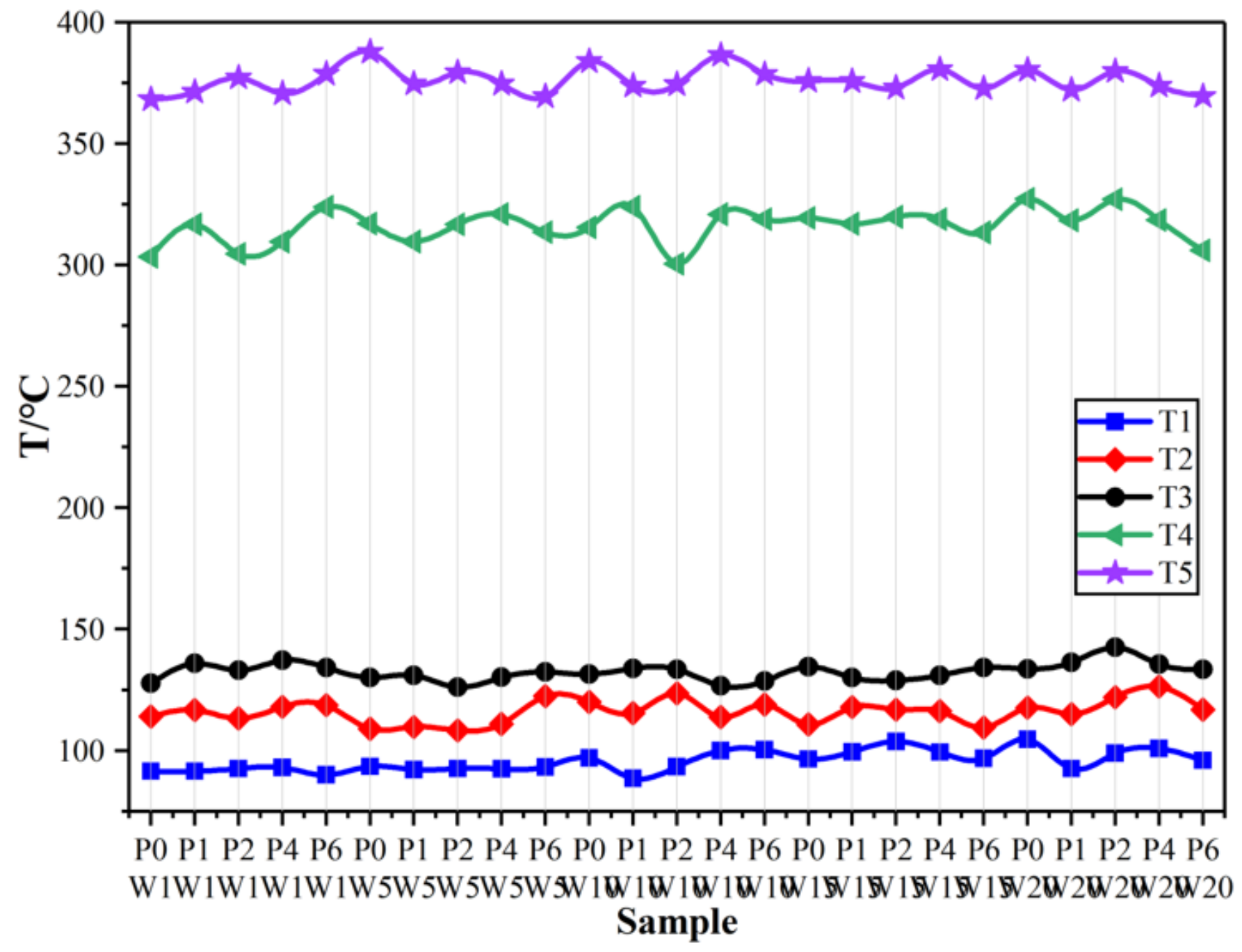

Figure 2

Characteristic temperatures of 25 coal samples 

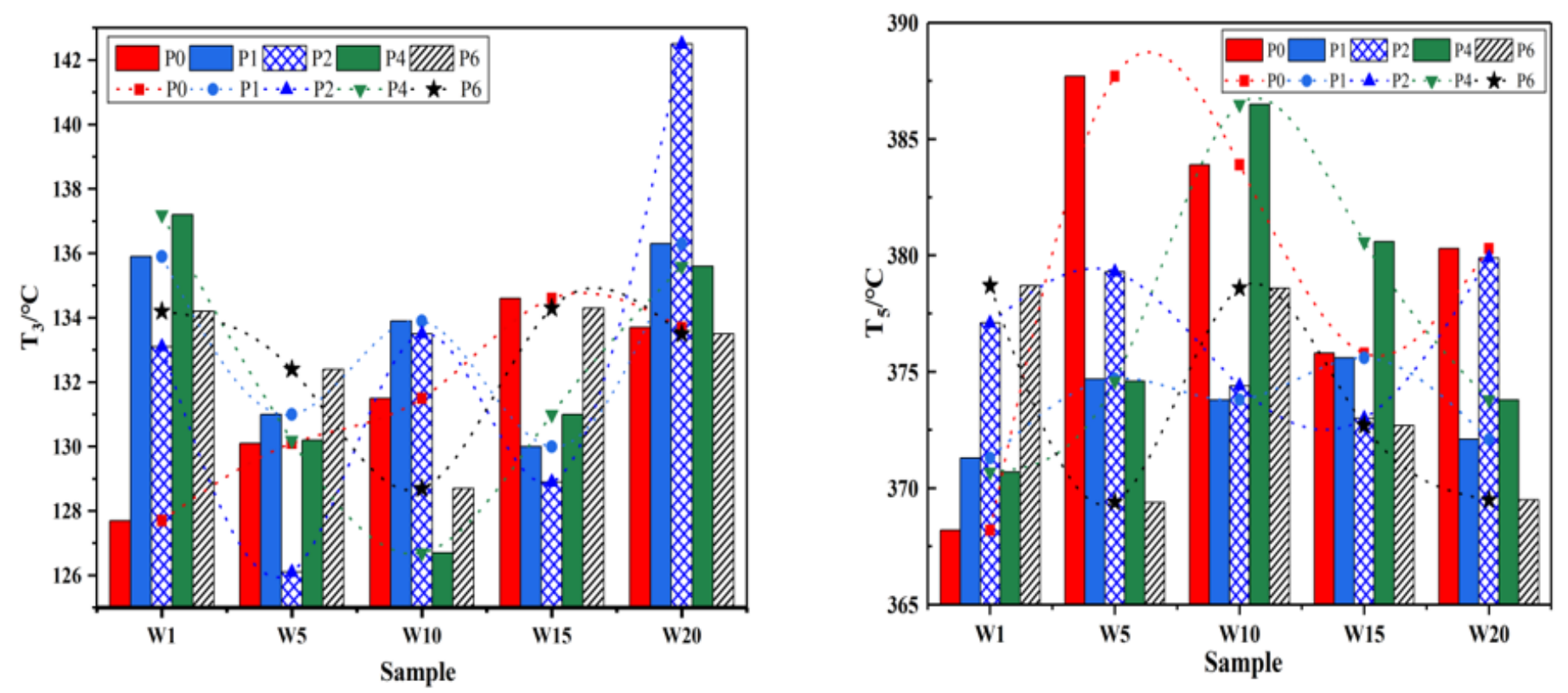

Figure 3

Characteristic temperature under different moisture and pyrite content
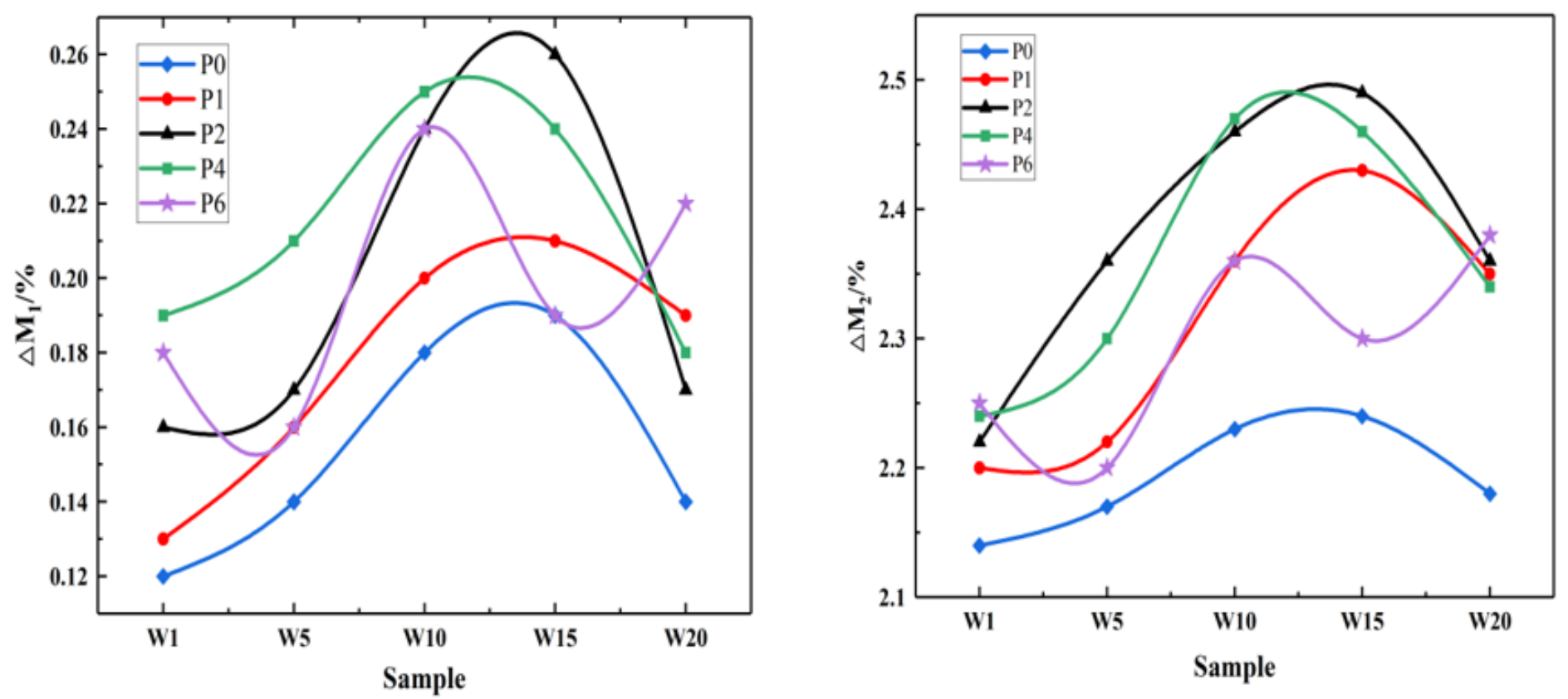

Figure 4

The mass variation of coal samples at different stages in the heating process 

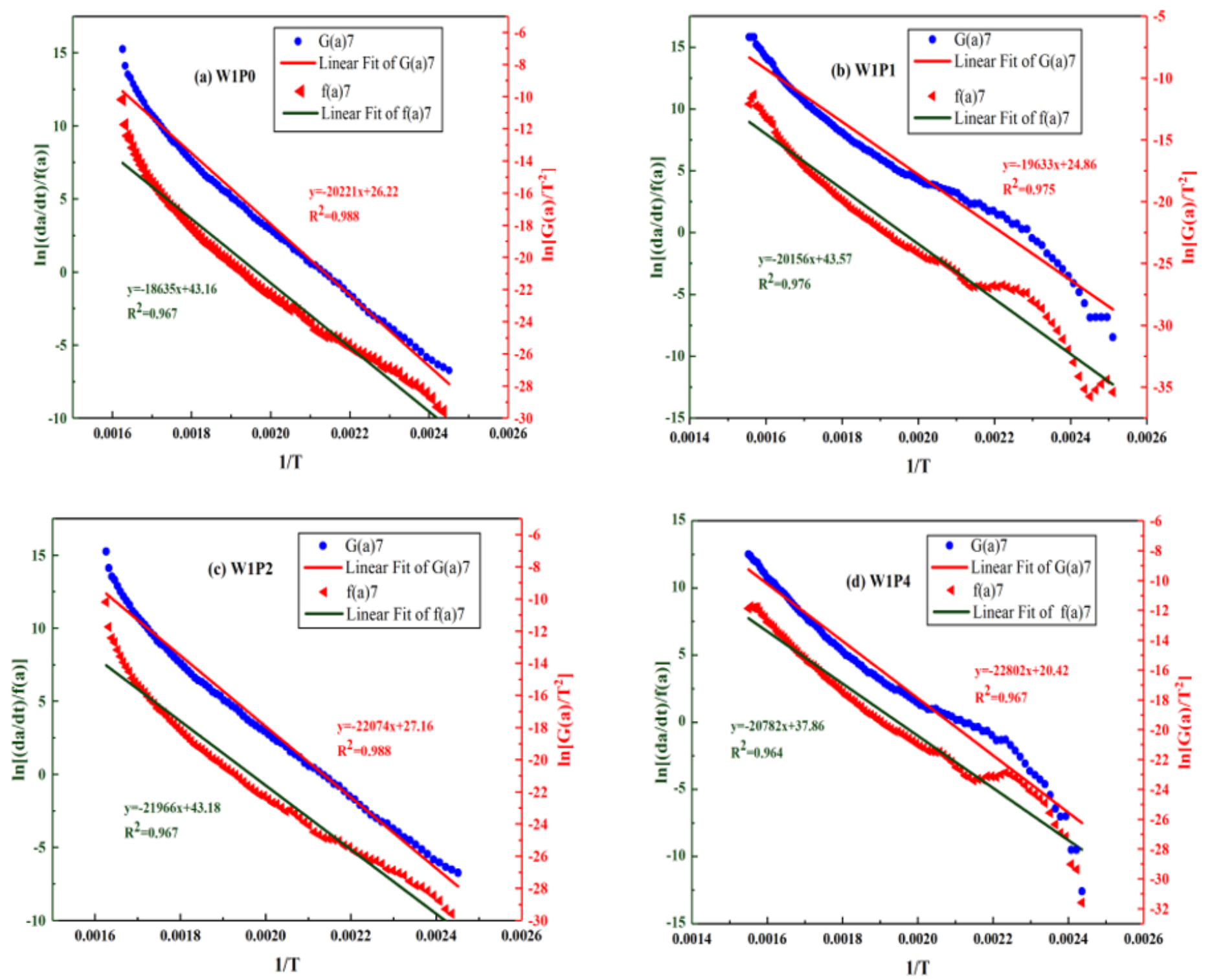

Figure 5

Oxygen absorption and weight gain stage $\ln [G(a) / T 2], \ln [(d a / d T) / f(a)]$ and $1 / T$ fittingcurve of some coal samples 


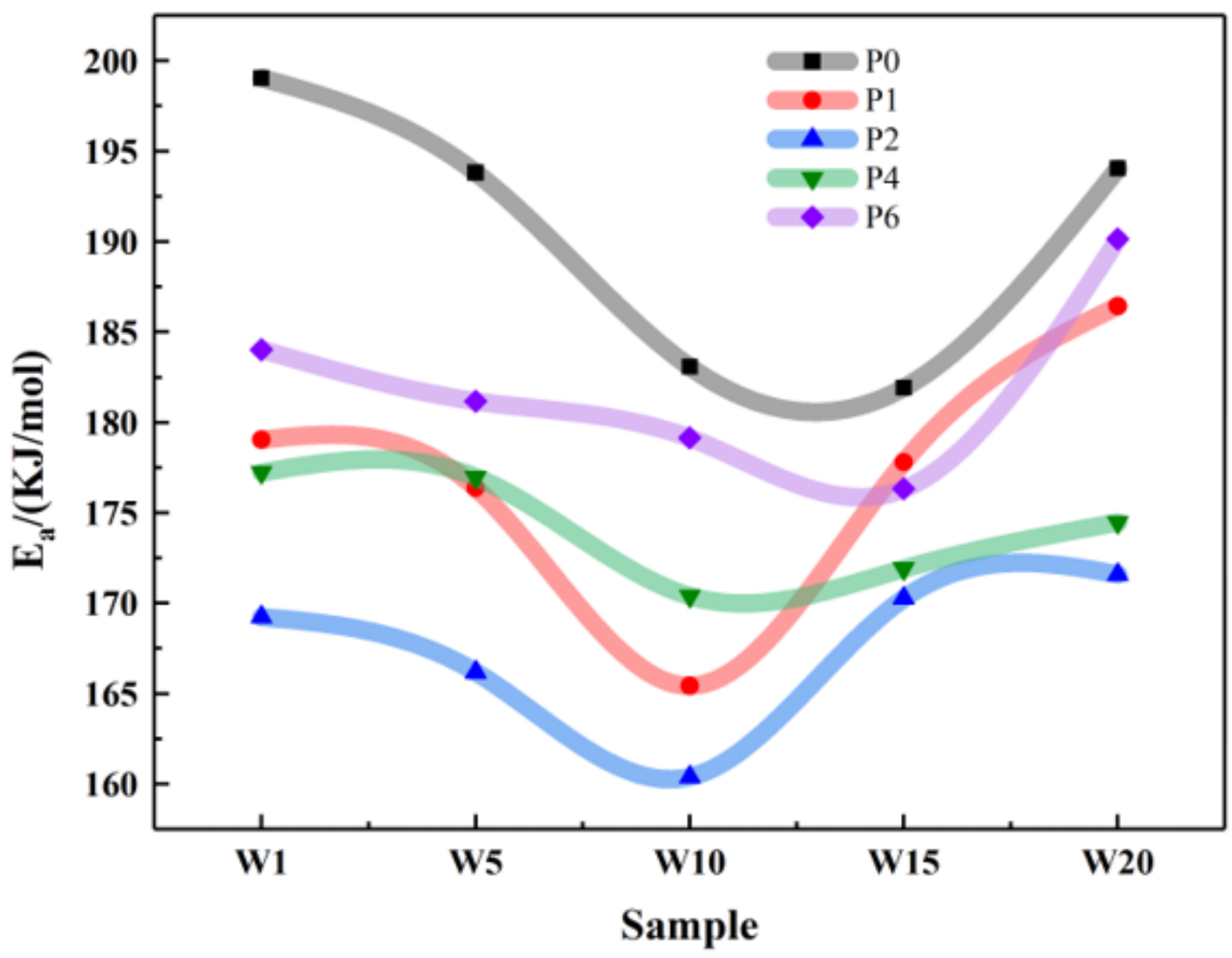

Figure 6

Changes of apparent activation energy of pyrite in coal sample oxidation process
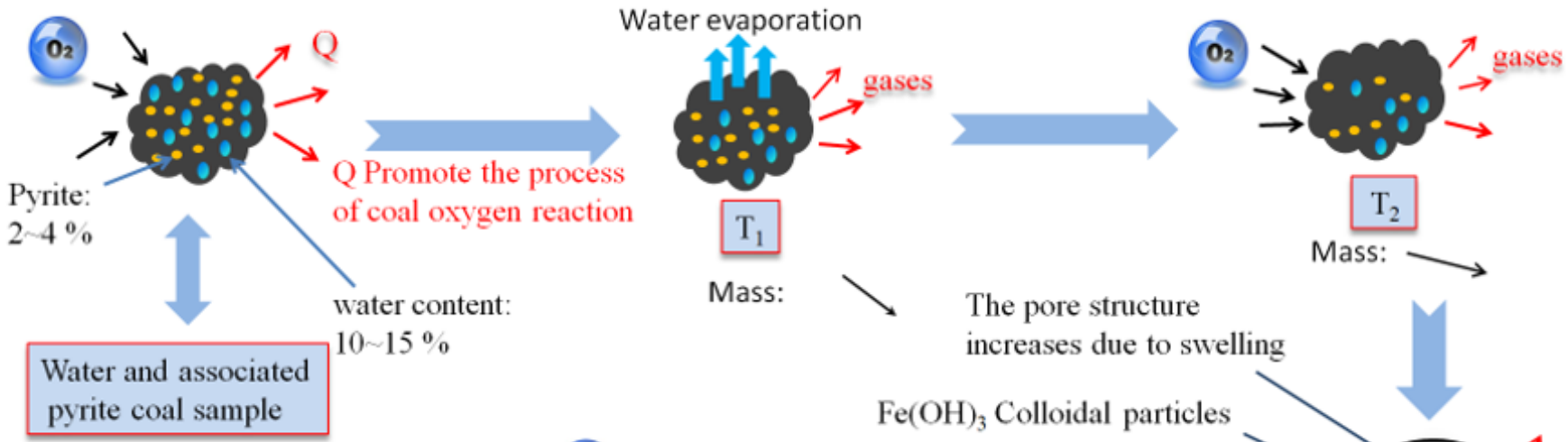

Mass:

Note:

Q: Heat release when water reacts with pyrite

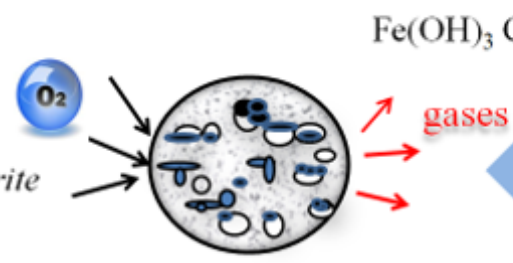

$$
\mathrm{T}_{5}
$$

Mass:

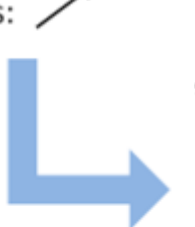

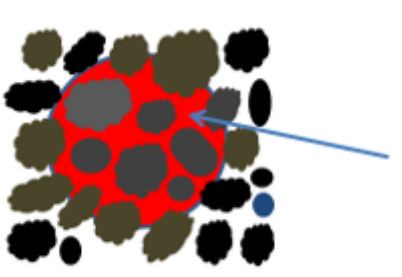

Coal spontaneous combustion 
Figure 7

Effect of water and associated pyrite on spontaneous combustion of coal

\section{Supplementary Files}

This is a list of supplementary files associated with this preprint. Click to download.

- Table3Commonsolidreactionmechanismfunctions.docx

- Table5Dynamicparametersofdifferentcoalsamples.docx 